\title{
Mudança institucional e atitudes políticas: a imagem pública da Assembleia Legislativa de Minas Gerais (1993-2006)
}

\author{
\begin{tabular}{c} 
Mario Fuks \\
\hline \hline Departamento de Ciência Política \\
Universidade Federal de Minas Gerais \\
Fabrício Mendes Fialho \\
Secretaria Estadual de Assistência e \\
Desenvolvimento Social de São Paulo, \\
Coordenadoria de Gestão Estratégica \\
\hline \hline
\end{tabular}
}

Resumo: $O$ artigo analisa o impacto das estratégias de comunicação realizadas pela Assembleia Legislativa de Minas Gerais (ALMG) durante a década de 1990 sobre a opinião pública da sociedade do estado de Minas Gerais. Pretende-se avaliar se a opinião pública em relação ao legislativo estadual se mostrou "resistente" às inovações institucionais ou se ocorreram mudanças ao longo dos treze anos cobertos pelos dados disponíveis. A análise comparativa no tempo e com outras instituições políticas não nos autoriza a falar sobre uma excepcionalidade da ALMG no que se refere a sua imagem pública. Em grande medida, a imagem da ALMG, em termos de confiança e avaliação, não foge do padrão brasileiro em relação às instituições políticas. O impacto do processo de inovação institucional é perceptível apenas sobre um público restrito: aqueles que consumiram as mensagens e comunicações produzidas pela ALMG e veiculadas no radio e na televisão.

Palavras-chave: cultura política; opinião pública; imagem institucional

\begin{abstract}
This article analyzes the impact on public opinion of the strategies of communication carried out by the Legislative Chamber of Minas Gerais (ALMG) during the 1990's. We evaluate whether the public opinion on the state legislature has changed along of this thirteen years, following a steady process of institutional innovation. Comparing results for different points of time between 1993 and 2006, we reject the idea that ALMG's public image is substantially different from standard public evaluation of Brazilian political institutions. We find that the institutional change process is noticeable and has a positive response only for the small public attentive to ALMG's messages transmitted by radio and television.
\end{abstract}

Keywords: political culture; public opinion, institutional image 


\section{Introdução}

O impacto das mudanças institucionais no sistema político de um país ou de uma localidade sobre as atitudes e, consequentemente, o comportamento político dos cidadãos estão associados à socialização política envolvida nesse processo (PATEMAN, 1992; PUTNAM, 1996). Como os ritmos dos dois processos (mudança institucional e socialização política) não são sincrônicos, a avaliação precisa de tal efeito não é tarefa fácil. Mesmo quando argumenta que as mudanças institucionais, na Itália da década de 1970, tiveram alcance limitado, Putnam observa que duas décadas não são tempo suficiente para se "detectar o impacto da reforma institucional no comportamento político" (PUTNAM, 1996, p. 194).

A complexidade da relação entre mudança institucional e comportamento político deve-se também ao fato de que, em geral, a mudança incide apenas sobre aspectos específicos do sistema político, muitos dos quais não afetam, de forma direta, a vida dos cidadãos. Nesses casos, espera-se que o impacto seja bem limitado.

Todavia, mesmo quando ocorrem em pequena escala e em arenas menos visíveis, mudanças institucionais acarretam alteração tanto no comportamento dos atores inseridos em tal ambiente como nas opiniões e atitudes políticas do público informado, em alguma medida, a respeito das transformações em curso.

O presente trabalho lida com essa temática a partir do estudo do impacto das inovações introduzidas, durante a década de 1990, na Assembleia Legislativa de Minas Gerais (ALMG) sobre as atitudes políticas dos mineiros. Essas inovações geraram uma mudança substantiva no padrão de interação entre a instituição e a sociedade civil organizada. Além disso, as inovações institucionais foram acompanhadas de um amplo elenco de estratégias de comunicação visando conferir-Ihes visibilidade pública. A questão a ser respondida é se esse contexto de mudança institucional gerou, no público mineiro, uma imagem mais positiva da ALMG.

Com isso, o artigo pretende explorar uma dimensão ainda pouco estudada na ciência política brasileira: a imagem pública de instituições políticas. Constituída a partir da interação entre a opinião pública e a comunicação política, o estudo sobre a imagem institucional nos permite analisar, de forma mais detalhada, os fenômenos e processos definidores da legitimidade das instituições políticas.

A primeira parte do texto apresentará, de forma resumida, o novo contexto institucional da ALMG, com ênfase nas novidades que criaram um novo padrão de interação com a sociedade civil e naquelas introduzidas na área de comunicação da instituição. Em seguida, apresentará os dados de uma série de surveys, de 1993 a 
2006, a respeito da imagem pública da ALMG. A análise desses dados constitui o núcleo do artigo, dividido em duas seções. Na primeira, analisamos o grau de interesse e informação e a avaliação do mineiro a respeito da ALMG, concluindo que não há indícios de que o processo de mudança institucional da ALMG tenha sido acompanhado por uma mudança substantiva na cultura política mineira. $\mathrm{Na}$ segunda, mostramos a heterogeneidade entre mineiros no que diz respeito à informação (que varia quando levamos em consideração fatores como escolaridade e renda) e o impacto da informação sobre a avaliação que se tem do trabalho realizado pela instituição.

Analisamos dados de pesquisas de opinião pública, contratadas pela ALMG e realizadas pelo Instituto Vox Populi nos anos de 1993, 1995, 2001, 2003 e 2006, representativos da população adulta do Estado de Minas Gerais ${ }^{1}$. Tais pesquisas trazem um amplo leque de questões sobre confiança em instituições, informação e conhecimento com relação a objetos políticos, bem como sobre opinião em relação ao desempenho dos mesmos.

As limitações da presente análise devem-se aos seguintes fatores: 1) a impossibilidade de acesso ao banco de dados, restando, como fonte, os relatórios, já com os dados tabulados; 2) nem todas as perguntas que nos interessam foram replicadas em todas as rodadas do survey; 3 ) os dados disponíveis não abrangem o período anterior à implementação das inovações institucionais.

Tais restrições - em especial a impossibilidade de acesso aos microdados das pesquisas - impediram que alguns testes fossem realizados, restringindo assim o escopo de nossa análise e a robustez de algumas de nossas interpretações. Tendo em vista essas limitações, nos propomos a apresentar apenas uma visão mais ampla da heterogeneidade do público mineiro e apontar, mesmo que de forma não conclusiva, o impacto também heterogêneo das estratégias de comunicação da instituição sobre públicos específicos. Pretendemos avançar na análise da heterogeneidade a partir de pesquisas com segmentos da sociedade mineira que têm um contato mais direto com a ALMG e estão mais expostos às ações de comunicação da instituição².

\footnotetext{
1 Para tamanho das amostras, margens de erro, intervalos de confiança, ponderações e data de realização das pesquisas, ver Anexo I.

2 Um dos estudos em curso tem como público os participantes do Parlamento Jovem. Promovido pela Escola do Legislativo, vinculada à Assembleia Legislativa de Minas Gerais, em parceria com o curso de Ciências Sociais da Pontifícia Universidade Católica (PUC Minas), o Parlamento Jovem é destinado aos alunos do ensino médio das escolas das redes pública e privada de Belo Horizonte. Além disso, estamos elaborando um survey com o objetivo de avaliar o impacto de eventos institucionais realizados pela Assembleia Legislativa de Minas Gerais sobre os participantes da sociedade civil organizada.
} 


\section{O novo contexto institucional e as estratégias de comunicação da ALMG}

No início da década de 1990, a ALMG criou um conjunto de eventos institucionais no sentido de promover uma interlocução contínua e substantiva com a sociedade mineira. Com tal objetivo, foram concebidos os Ciclos de Debates, as Audiências Públicas Regionais, os Seminários Legislativos e os Fóruns Técnicos, sendo que esses dois últimos culminam na elaboração de projetos de lei.

Previstas na Constituição estadual, as Audiências Públicas Regionais, que ocorreram entre 1993 e 1997, traduzem bem o espírito que norteava o processo de inovação que estava em curso na Assembleia Legislativa de Minas Gerais. Participavam das Audiências as prefeituras, as câmaras municipais e as entidades representativas da sociedade civil das diversas regiões do estado, contribuindo para a descentralização do processo de elaboração da lei orçamentária ${ }^{3}$.

Mais recentemente, em 2003, foi instituída a Comissão Permanente de Participação Popular, que, entre outras atribuições, acolhe as iniciativas legislativas de entidades da sociedade civil e encaminha essas demandas para a tramitação legislativa. Nesse mesmo ano, a Comissão implementou a audiência pública do Plano Plurianual de Ação Governamental, convidando setores da sociedade civil para discutir a proposta do Executivo, sugerir alterações, fazer novas propostas e acompanhar a execução do planejamento aprovado ${ }^{4}$.

Além da democratização da instituição, tornando-a mais permeável à participação da sociedade civil na produção legislativa, a ALMG também investiu sistematicamente na sua modernização e profissionalização. Em 1992, a Assembleia mineira criou a primeira Escola do Legislativo do país, oferecendo formação e qualificação profissional para o seu corpo técnico ${ }^{5}$, além de desenvolver uma série de atividades pedagógicas no sentido de fomentar a "educação para a cidadania" (ASSIS, 1997) ${ }^{6}$.

A separação entre corpo técnico e política é, certamente, um dos marcos desse processo. Já em 1987, a Deliberação da Mesa 342/87 limita a lotação de servidor efetivo em gabinete parlamentar ${ }^{7}$, e, em 1990, por meio da resolução 5.086/90, a Assembleia Legislativa de Minas Gerais instituiu que, além de concursado, o seu corpo técnico não mais serviria os gabinetes dos deputados e

\footnotetext{
${ }^{3}$ Assembleia Legislativa de Minas Gerais, Desenvolvimento Institucional da Assembleia Legislativa do Estado de Minas Gerais, relatório de 1994, p. 11.

4 Processo licitatório n. ${ }^{\circ} 056 / 2006$, concorrência n. ${ }^{\circ} 004 / 2006$, p. 3.

${ }^{5}$ Assembleia Legislativa de Minas Gerais, Desenvolvimento Institucional da Assembleia Legislativa do Estado de Minas Gerais - 1988 a 1998, relatório de 1999.

6 Esse é o propósito de programas como o Cidadão-Mirim, o Parlamento Jovem e a distribuição de vídeos educativos para as escolas da rede estadual de ensino de Minas Gerais.

${ }^{7}$ Assembleia Legislativa de Minas Gerais. Estrutura Organizacional e Visão Institucional da ALMG, 2002.
} 
sim a estrutura administrativa da Casa. Ainda no início da década de 1990, a ALMG realizou concursos públicos para contratar técnicos especializados nas diversas áreas temáticas da produção legislativa.

Outro esforço pioneiro foi a informatização da Assembleia, iniciado em 1979, por meio de convênio estabelecido com o Prodasen (DULCI e FARIA, 2005), e consolidado com a disponibilização de todos os atos legislativos, desde os projetos de leis aos anais da ALMG, no site da Assembleia.

O conjunto dessas inovações colocou a ALMG, no decorrer da década de 1990, na "vanguarda" dos legislativos estaduais brasileiros. Mas, considerando que inovações institucionais não geram, automaticamente, mudanças nas atitudes políticas dos cidadãos, a aproximação mais efetiva da ALMG com a sociedade mineira dependeria ainda de ações na área de comunicação, envolvendo a produção e veiculação de mensagens políticas com a finalidade de tornar a ALMG mais visível e promover uma imagem pública mais favorável da instituição. Isso porque, enquanto os eventos legislativos, restritos a um público específico da sociedade, orientam-se por uma visão de mudança de longo prazo na cultura política, somente as estratégias de comunicação são capazes de gerar, no curto prazo, mudanças na opinião pública.

Não por acaso, no projeto de inovação institucional, o setor de comunicação da ALMG sempre teve papel de destaque. Também não foi por mera coincidência que, em 1990, a ALMG contratou a empresa de consultoria Lélio Fabiano \& Associados para a realização do Planejamento Estratégico de Comunicação Social da Assembleia ${ }^{8}$.

Esse Planejamento, que estabeleceu os princípios e indicou medidas que nortearão as atividades desenvolvidas ao longo da década de 1990, sugere a criação de um setor de comunicação autônomo e profissional. Somente com essa equipe de profissionais e a criação de uma estrutura específica para lidar com a questão da comunicação, interna e externa, a ALMG seria capaz de "reverter a imagem negativa que ora se apresenta" ${ }^{9}$. Seguindo essa orientação foi criado, em 1990, o Departamento de Comunicação Social da ALMG.

Durante a década de 1990, a ALMG montou um potente sistema de comunicação, contando com uma série de meios de produção e veiculação de informação para o público externo. Em novembro de 1995, a Assembleia Legislativa

\footnotetext{
8 Essa não foi a única vez que a ALMG recorreu à consultoria especializada para lidar com o desafio da modernização organizacional. Em 1993, a Assembleia contratou a empresa Arthur Andersen visando a "reorganização e racionalização de seus serviços e de sua estrutura, consolidando posições organizacionais e perfis gerenciais" (Assembleia Legislativa de Minas Gerais, Desenvolvimento institucional da Assembleia Legislativa do Estado de Minas Gerais, p.7, 1994).

9 Lélio Fabiano \& Associados Comunicação Empresarial, Planejamento Estratégico de Comunicação Social para a Assembleia Legislativa de Minas Gerais, relatório, p.2, 1990.
} 
de Minas Gerais inaugurou o primeiro canal legislativo da América Latina ${ }^{10}$, antecedendo até mesmo a TV Senado do Brasil ${ }^{11}$ (JARDIM 2006; RENAULT, 2004). Além disso, a ALMG conta com Rádio Assembleia, um dos dois sites classificados como de "alto grau de informatização" entre os legislativos estaduais brasileiros (BRAGA, 2004) e um amplo leque de publicações impressas ${ }^{12}$.

Outra importante iniciativa da área de comunicação da ALMG foi a contratação, em 2002, de duas agências de publicidade, visando dinamizar a comunicação com a população mineira. O edital de concorrência ressaltava, de um lado, as realizações do setor de comunicação da ALMG ao longo de dez anos . "primeiro programa de televisão, primeira revista, primeiro sistema de informações on-line, primeira homepage, primeira TV legislativa" - e, de outro, a necessidade de buscar novos caminhos para a divulgação de sua imagem pública. Pois,

\section{"[...] a Assembléia nunca conseguiu com eficiência emplacar um conceito forte perante a sociedade. A idéia que se tem da Casa - a julgar pela análise que dela fazem os licitantes em suas análises neste processo - é que seus propósitos, embora fortes e elogiáveis, não são percebidos pela sociedade"13.}

No briefing do edital de licitação, é expresso o objetivo de mudar esse cenário adverso, por meio da disseminação junto à população da "ideia de uma Assembleia trabalhadora e eficiente em suas ações" e "aberta à participação do cidadão e capaz de responder com agilidade às demandas e pressões populares".

Recentemente, no final de 2006, a ALMG abriu um novo processo licitatório para contratação de firmas de publicidade ${ }^{14}$. O "problema" na área de comunicação, constatado por pesquisa de opinião e que deveria ser enfrentado pela firma contratada, é a falta de informação e a imagem negativa que a população mineira tem da ALMG, a despeito de todo o esforço de comunicação empreendido pela Assembleia até então.

A preocupação com uma administração profissional da imagem pública da instituição não tem se restringido à contratação de agências de publicidade, incluindo também a realização periódica de surveys ${ }^{15}$ no sentido de identificar as percepções, opiniões e valores da população mineira a respeito da ALMG.

\footnotetext{
${ }^{10}$ Criado logo após a publicação da Lei 8.977/95 (Brasil, 1995).

${ }^{11}$ A TV Senado entrou em operação em fevereiro de 2006.

12 Incluindo, entre outras publicações, a Revista do Legislativo, os Cadernos da Escola do Legislativo e a Assembleia na Imprensa.

13 Processo licitatório $n^{\circ}$ 72/2001. Edital de concorrência 003/2001 da Assembleia Legislativa de Minas Gerais para a contratação de duas agencias de publicidade. Anexo I: Projeto Básico (briefing), p. 3.

14 Processo licitatório n 056/2006. Edital de concorrência n 004/2006.

15 Os quais constituem a principal fonte para a análise desenvolvida neste trabalho.
} 
Dentre todas as iniciativas da área de comunicação da ALMG, merece destaque o programa Assembleia Informa. Esse noticiário institucional, com duração de 2 minutos, foi exibido, de segunda a sexta-feira, nas emissoras comerciais do estado entre outubro de 1991 e outubro de 2001. Com mais de duas mil edições, o Assembleia Informa divulgou, durante esses dez anos, informações sobre as atividades do legislativo mineiro. O programa tinha também uma versão para rádio. Além disso, a ALMG publicou, no mesmo período, matéria paga semanal no jornal de maior circulação no estado, o Estado de Minas, intitulada Acontece na Assembleia. Esse conjunto de informações veiculadas na mídia comercial constitui, provavelmente, a ação de maior envergadura já empreendida por um legislativo estadual no Brasil no sentido de conferir visibilidade pública à instituição ${ }^{16}$.

Seria de se esperar que a excepcionalidade da experiência parlamentar mineira, em associação com poderosos recursos de comunicação, fosse acompanhada por uma mudança perceptível da opinião pública. É exatamente esse o foco do nosso estudo: se, e em que medida, esse amplo leque de inovações institucionais e estratégias de comunicação causou impacto sobre a imagem pública da ALMG. Como veremos na análise que segue, tal mudança de imagem não ocorreu da forma esperada e, muito menos, de forma homogênea entre a população mineira.

\section{A imagem pública da ALMG}

Qual é a imagem pública da ALMG? Houve alguma alteração dessa imagem ao longo do tempo? Os dados não poderiam ser mais eloquentes: desde 1993, uma incômoda maioria expressa atitudes negativas em relação ao legislativo estadual. Essa maioria - um número nunca inferior a $64 \%$ - confia pouco ou não confia na Assembleia Legislativa de Minas Gerais (Tabela 1).

\footnotetext{
16 Não por acaso, o Conselho Regional de Profissionais de Relações Públicas dos Estados de São Paulo e do Paraná "concederam à Assembleia mineira o Prêmio Opinião Pública 94 - distinção dada aos melhores trabalhos de relações públicas realizados em benefício de empresas e instituições privadas ou governamentais do Brasil". Documento elaborado pela Secretaria de Comunicação Institucional da ALMG, Desenvolvimento institucional da Assembleia Legislativa do Estado de Minas Gerais, outubro de 1994.
} 
Tabela 1

Confiança em instituições políticas (\%)

\begin{tabular}{|l|c|c|c|c|c|c|}
\cline { 2 - 8 } \multicolumn{1}{c|}{} & \multicolumn{4}{c|}{ ALMG } & \multicolumn{3}{c|}{ Congresso Nacional } \\
\cline { 2 - 8 } \multicolumn{1}{c|}{} & 1993 & 2003 & 2006 & 1993 & 2003 & 2006 \\
\hline Confia sempre & 13 & 10 & 6 & 10 & 8 & 4 \\
\hline Confia na maior parte do tempo & 12 & 16 & 15 & 9 & 15 & 11 \\
\hline Confia pouco & 26 & 37 & 34 & 25 & 35 & 32 \\
\hline Não confia nunca & 38 & 31 & 38 & 47 & 36 & 47 \\
\hline NS / NR & 11 & 6 & 6 & 10 & 6 & 6 \\
\hline N & 1.153 & 5.000 & 6.300 & 1.153 & 5.000 & 6.300 \\
\hline
\end{tabular}

Fonte: Vox Populi, 1993, 2003, 2006.

Mas, o mais importante para a nossa análise é saber se houve - e em qual direção - alguma evolução temporal da confiança dos mineiros em relação à ALMG. Na verdade, a mudança que se percebe, ao longo do tempo, é no sentido contrário, expressa na tendência de redução daqueles que "confiam sempre" na instituição. Não podemos, portanto, sustentar que as inovações institucionais e as estratégias de sua divulgação tenham sido acompanhadas por alterações significativas na confiança que a sociedade mineira deposita na ALMG.

Isso, no entanto, não nos autoriza a concluir que as mudanças institucionais não tenham causado algum impacto positivo na percepção do público mineiro. Se incluirmos, na análise dos dados, a influência de fatores conjunturais, certas mudanças de opinião tornam-se mais compreensíveis. Assim, o fato de 2006 ter sido o ano em que a confiança na Assembleia atingiu os níveis mais baixos pode, em parte, estar associado ao declínio generalizado da confiança nas instituições políticas brasileiras, gerado pela crise política ocorrida nesse período, como atesta a Tabela $1^{17}$.

Também não podemos ignorar nessa análise fenômenos e eventos políticos regionais relevantes e que, eventualmente, possam estar "concorrendo" com o esforço de aperfeiçoamento institucional. Seguindo essa linha de análise, o decréscimo de confiança apontado no survey de 2003 pode ainda refletir os efeitos

\footnotetext{
17 Além disso, flutuações constantes nas atitudes a respeito das instituições políticas têm sido um fenômeno observado na América Latina Em relação à confiança nos parlamentos nacionais, o Latinobarômetro apresenta as seguintes médias para a América Latina: 1997, 36\%; 1998, 27\%; 1999. 2000, 28\%; 2001, 24\%; 2002, 23\%; 2003, 17\% (POWER \& JAMISON, 2005, p. 72).
} 
negativos do escândalo dos mega-salários, em 2001, envolvendo os deputados estaduais de Minas Gerais ${ }^{18}$.

Se, por um lado, essas considerações servem para relativizar o tom pessimista de conclusões precipitadas, por outro, os dados disponíveis excluem a possibilidade de afirmar que tenha havido, a partir de 1993, uma mudança favorável na confiança dos mineiros em relação ao poder legislativo estadual. Isso significa que o processo de inovação institucional não foi condição suficiente para desencadear uma transformação perceptível nas atitudes políticas dos mineiros.

Se os nossos dados longitudinais não nos permitem retroceder para o período anterior a $1993^{19}$, podemos, ao menos, comparar, num mesmo período, a confiança na ALMG com a confiança dos mineiros em relação ao Congresso Nacional. Encontramos sempre níveis próximos - igualmente baixos ·, embora a confiança no parlamento nacional seja menor. Em 1993, por exemplo, $72 \%$ dos mineiros manifestavam desconfiança em relação ao Congresso Nacional e, em 2003, $71 \%^{20}$. Mas, esse não é apenas um padrão regional; ao contrário, parece ser o padrão recorrente nas atitudes dos brasileiros em relação às instituições políticas. Em 1996, a sondagem de opinião pública conduzida pelo Latinobarômetro revelou que $72 \%$ dos brasileiros tinham pouca ou nenhuma confiança no Congresso Nacional ${ }^{21}$ (MOISÉS, 2006).

\footnotetext{
18 O escândalo dos mega-salários iniciou no dia $1^{\circ}$ de agosto de 2001 , a partir de matéria de capa veiculada pelo jornal Estado de Minas, logo ganhando destaque na mídia nacional. O levantamento dos dados da pesquisa referente ao ano de 2001 foi realizado no início do mês de outubro - ou seja, apenas 2 meses após o "estouro" do escândalo e sua veiculação nos meios de comunicação. Vê-se, assim, a repercussão imediata do evento sobre a opinião pública mineira a respeito da ALMG. Em etapa posterior dessa pesquisa, que tratará da cobertura jornalística do Estado de Minas sobre a Assembleia no período 1991-2006, teremos oportunidade de explorar de forma mais sistemática aspectos relacionados a este ponto. Para um estudo a respeito do escândalo dos mega-salários, ver Sousa (2007).

19 Não dispomos de dados de survey para o período que antecede o processo de mudança institucional e a implementação de estratégias de comunicação por parte da ALMG. Portanto, não sabemos se houve aumento ou declínio de confiança na ALMG com a introdução das inovações. Nossas evidências são, portanto, indiretas, a partir da evolução das atitudes dos mineiros durante o período investigado e, principalmente, da comparação com as atitudes dos mineiros e brasileiros em relação às demais instituições políticas.

20 Pesquisa realizada na Região Metropolitana de Belo Horizonte pela Universidade Federal de Minas Gerais, em 2005, mostrou uma atitude ainda mais acentuada de desconfiança dos mineiros em relação às instituições políticas nacionais. Assim, apenas $8 \%$ dos entrevistados confiavam sempre ou na maior parte do tempo no Congresso Nacional, enquanto $45,7 \%$ nunca confiavam na instituição.

21 A Pesquisa Social Brasileira, realizada em 2002, revelou um quadro de desconfiança ainda mais acentuada. Nela, $86 \%$ dos brasileiros declararam não confiar ou confiarem pouco no Congresso Nacional. Mesmo considerando que essas pesquisas tenham sido realizadas em contextos político, econômicos e sociais específicos, o fato irrefutável é a permanência de uma atitude de desconfiança nas instituições legislativas brasileiras. Não devemos, no entanto, concluir, de forma precipitada, que está em curso um processo de erosão das bases de legitimidade das instituições políticas brasileira, mas há que considerar que a desconfiança no Brasil, assim como na América Latina de forma geral (ver LAGOS, 2000), é um fenômeno de natureza global, assumindo a forma de uma "cultura da desconfiança". Assim, a desconfiança política, na região, "não está em desacordo com as normas sociais mais amplas" (POWER \& JAMISON, 2005, p. 74). Um exemplo emblemático, no caso brasileiro, é a desconfiança
} 
Esse quadro pouco favorável à ALMG é, portanto, reforçado pelo fato de que a imagem da Assembleia não difere muito daquela que os mineiros têm do Congresso Nacional. Ou seja, não prevalece uma visão diferenciada da ALMG, de forma a isolá-la das opiniões dominantes em relação às instituições políticas brasileiras. Por outro lado, o diferencial de confiança favorável à ALMG em comparação com o Congresso Nacional, embora pequeno, pode ser um indício de que o mineiro, ainda que de forma vaga e tímida, identifica, no legislativo estadual, algo de positivo que o diferencie de outras instituições políticas.

Além da confiança na instituição, os dados de que dispomos permitem também analisar a avaliação da ALMG. Sendo essa mais complexa do que o sentimento de confiança, pois envolve a articulação entre a dimensão cognitiva e a dimensão afetiva (ALMOND e VERBA, 1963) da atitude política, é compreensível o alto número de não respondentes, atingindo 18\% tanto em 2003 como em 2006.

Considerando a avaliação global dos entrevistados sobre o desempenho da ALMG na realização de suas funções e atividades, verifica-se uma tendência de queda da avaliação positiva da instituição por parte dos entrevistados. Tendo 1995 como referência, a avaliação positiva (ótimo e bom) decresce e a regular (positiva e negativa) aumenta nos anos posteriores. 0 ano de 2001 aparece, de certa forma, como atípico nessa série temporal, pois acentua ainda mais a avaliação negativa, expressa pelo aumento das avaliações "ruim" e, sobretudo, "péssima".

Nota-se como a "curva de opinião" para o ano de 2001 apresenta formato diferente dos demais anos da série. Trata-se do único ano em que a avaliação do desempenho da ALMG como "bom" fica abaixo dos 15\%, enquanto o "ruim" e o "péssimo" situam-se no nível mais alto da avaliação (Gráfico 1).

interpessoal. De acordo com os dados para 1996, apenas 5\% dos brasileiros declaravam confiar nas pessoas. De toda forma, esse quadro não singulariza a América Latina ou, em particular, o Brasil, pois a desconfiança nas instituições legislativas tem sido identificada como um traço comum nas maiorias das democracias desde a década de 1990 (KLINGEMANN, 1999). 
Gráfico 1

Impacto do escândalo dos "mega-salários" sobre avaliação de desempenho da ALMG (\%)

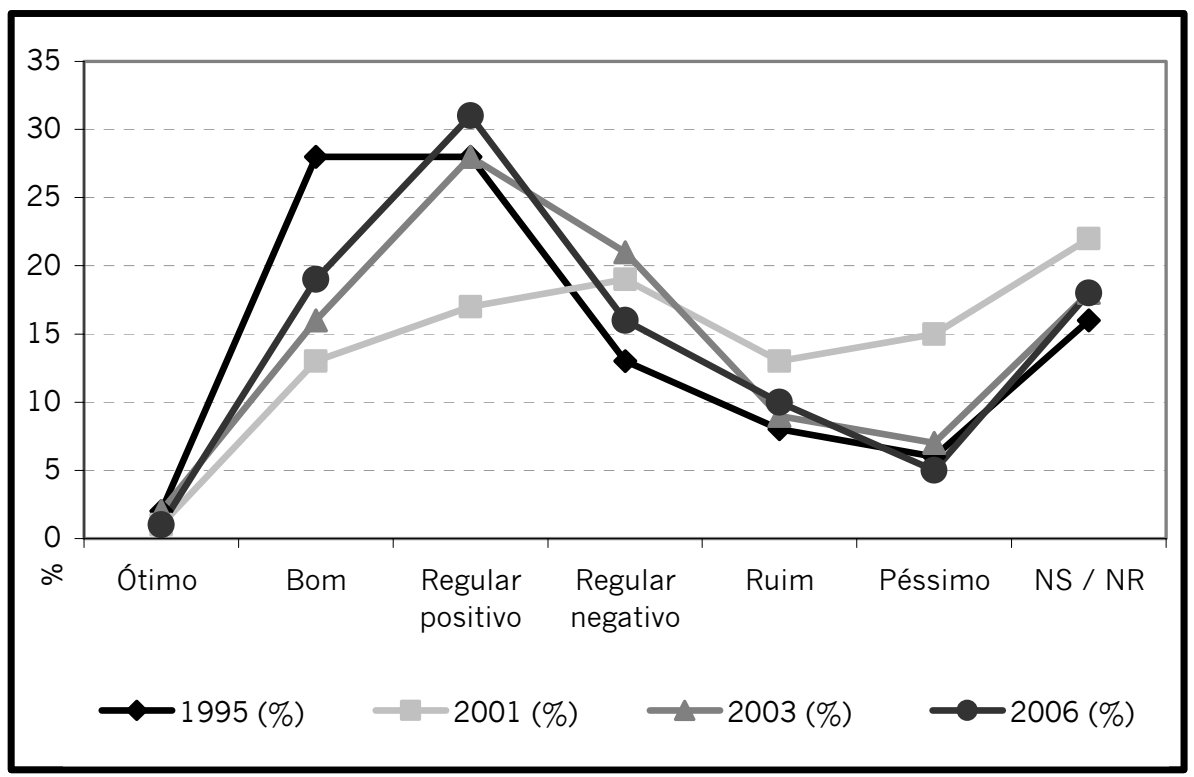

Fonte: Vox Populi, 1995,2001,2003,2006.

O único fenômeno que singulariza o ano de 2001 ao longo do período é o escândalo dos mega-salários. Portanto, podemos cogitar que exista associação entre a queda substantiva da avaliação da ALMG em 2001 e o escândalo. Tal associação sugere um impacto desigual dos conteúdos da comunicação política: enquanto intensos e diversificados esforços empreendidos no sentido de veicular notícias positivas geram, quando muito, efeitos limitados, um único evento negativo tem efeito devastador sobre a imagem pública de uma instituição.

Apesar dessa queda da avaliação do trabalho desenvolvido pela ALMG, quando se solicitou aos entrevistados que comparem o trabalho atual da ALMG com - trabalho de dez anos atrás, apenas uma minoria (em torno de 15\% dos entrevistados) considera que a ALMG piorou (Tabela 2). 
Tabela 2

Avaliação comparativa da ALMG em relação a dez anos atrás (\%)

\begin{tabular}{|l|l|l|l|l|}
\cline { 2 - 5 } \multicolumn{1}{c|}{} & $\mathbf{1 9 9 5}$ & $\mathbf{2 0 0 1}$ & $\mathbf{2 0 0 3}$ & $\mathbf{2 0 0 6}$ \\
\hline Melhor & 32 & 21 & 31 & 22 \\
\hline Igual & 26 & 20 & 33 & 38 \\
\hline Pior & 16 & 25 & 14 & 16 \\
\hline NS / Não lembra & 26 & 32 & 21 & 24 \\
\hline N & 1.550 & 1.500 & 5.000 & 6.300 \\
\hline
\end{tabular}

Fonte: Vox Populi, 1995, 2001, 2003, 2006.

Pergunta: "Pelo que você observa ou ouve falar, o trabalho que a Assembleia Legislativa vem desenvolvendo atualmente tem sido melhor, igual ou pior do que há 10 anos?"

Novamente, o ano de 2001 é o momento mais desfavorável (com menor índice de "melhor" e maior de "pior") para a imagem da Assembleia. Aliás, a excepcionalidade do ano 2001 parece ser a única conclusão inquestionável apontada pelos dados. A recuperação, em 2003, evidencia que os dados de 2001 refletem o impacto significativo de fatores específicos do período, como sugerimos anteriormente.

Uma análise mais detalhada do survey de 2006 indica que também nesse a redução nas percepções positivas da situação presente está associada a escândalos políticos. A má impressão geral sobre a política, em especial sobre o Congresso, reverbera sobre as demais instituições, inclusive na ALMG.

Esse efeito de "contaminação" indica que parcela substantiva da população mineira não estabelece uma clara diferenciação entre objetos políticos de natureza distinta $^{22}$. Se as esferas estadual e federal da atividade legislativa aparecem como indissociáveis, podemos supor que o mesmo padrão de percepção associe os agentes políticos e a instituição a que pertencem. Portanto, além da contaminação "vertical", que se dá entre instituições políticas de diferentes níveis, há também a contaminação intra-institucional. Nesse sentido, a imagem que os cidadãos têm dos deputados e do corpo técnico da ALMG deve influenciar a imagem pública da Assembleia Legislativa de Minas Gerais.

Como aponta o survey de 1993, a insatisfação com os parlamentares é tão expressiva que menos de um quinto (17\%) dos mineiros disseram estar satisfeitos com o trabalho dos deputados estaduais que conhece. Essa insatisfação é reiterada na pergunta que se refere, especificamente, às críticas que usualmente são feitas aos deputados. Os mineiros acreditam que, em geral, os deputados estaduais

22 A noção de "contaminação" empregada aqui aparece anteriormente em Vox Populi (1993). 
recebem comissões ou propinas de empreiteiros ou fazendeiros (67\%), só se interessam por dinheiro (81\%), só se preocupam com o eleitor em época de eleição (89\%), compram votos para se eleger (76\%), não cumprem as promessas que fazem antes da eleição (86\%), não comparecem à Assembleia nem para votarem projetos (53\%) e "trocam de partido como trocam de camisa" (74\%).

Da mesma forma, na avaliação dos funcionários da ALMG, os mineiros endossam as críticas correntes. A grande maioria dos entrevistados percebe 0 funcionário da ALMG como um privilegiado (72\%), apadrinhado (71\%), enquanto apenas uma minoria o considera como uma pessoa trabalhadora (26\%).

Infelizmente, os dados sobre avaliação dos deputados e funcionários estão presentes apenas no survey de 1993. Portanto, não temos condições de avaliar se, em outros momentos, o processo de inovação institucional afetou, positivamente, a imagem pública dos deputados estaduais e dos funcionários da Assembleia. Mas, sendo tão eloquentes, esses dados nos convidam a pensar na influência no sentido inverso, da imagem desse atores sobre a imagem da Assembleia. Temos, portanto, razão para suspeitar que a percepção que os mineiros têm do comportamento individual dos parlamentares e do corpo técnico da ALMG se constitui como um entrave para a pretendida mudança de imagem pública da instituição.

\section{Diversidade de públicos}

Mas, seriam essas atitudes políticas distribuídas de forma homogênea pela população mineira? Para lidar com esse tipo de questão, podemos começar nos perguntando se e em que medida os mineiros se interessam e consomem informação sobre a Assembleia Legislativa de Minas Gerais. Partindo do pressuposto de que o impacto da informação política veiculada varia em função do grau de atenção dos diversos públicos (ZALLER, 1996), qual seria o universo de cidadãos mineiros que acompanha o que acontece no legislativo estadual? Conforme apontam os dados, esse universo é bastante restrito. Em 1993, mais da metade dos mineiros não tinham o hábito de se informar sobre o que acontece na ALMG (Tabela 3). 
Tabela 3

Canais de Informação sobre a ALMG, 1993

\begin{tabular}{|l|c|}
\hline & $\%$ \\
\hline Não costuma se informar & 56 \\
\hline Jornal da cidade & 2 \\
\hline Jornal da capital & 10 \\
\hline Rádio & 5 \\
\hline TV & 32 \\
\hline Conversas com amigos & 8 \\
\hline N & 1.153 \\
\hline
\end{tabular}

Fonte: Vox Populi, 1993.

Pergunta: "Como você costuma se informar sobre o trabalho que os deputados estaduais realizam na assembleia?". A questão possibilitava múltiplas respostas para aqueles que declaravam ter o costume de se informar sobre o trabalho da ALMG.

A pesquisa realizada em 1995 revela um mesmo padrão: 1) mais da metade da sociedade mineira, $65 \%$, têm pouco ou nenhum interesse, nem costuma se informar a respeito do que acontece na Assembleia (54\%) (Tabela 4); 2) os mineiros usam a televisão como principal canal de informação a respeito do legislativo estadual; 3) a mídia impressa, o rádio e a conversa com amigos constituem fontes de informação complementar para aqueles que se mantêm informados a respeito do que acontece na ALMG (Tabela 5).

Tabela 4

Interesse por notícias sobre o trabalho realizado na ALMG

\begin{tabular}{|l|c|}
\hline & $\mathbf{\%}$ \\
\hline Tem muito interesse & 10 \\
\hline Interesse & 22 \\
\hline Pouco interesse & 41 \\
\hline Nenhum interesse & 24 \\
\hline NS / NR & 3 \\
\hline $\mathrm{N}$ & 1.550 \\
\hline
\end{tabular}

Fonte: Vox Populi, 1995.

Pergunta: "Nos últimos 3 meses, você tem lido, visto ou ouvido alguma notícia sobre a Assembleia Legislativa, seja na TV, rádio, em jornais ou qualquer outra forma? (se sim, através de que meios de comunicação você tem recebido notícias sobre a Assembleia?)". 
Tabela 5

Canais de Informação sobre a ALMG, 1995

\begin{tabular}{|l|c|}
\hline & $\%$ \\
\hline Não tem tido & 54 \\
\hline Através de tv & 39 \\
\hline Jornais & 14 \\
\hline Assembleia Informa & 14 \\
\hline Noticiário de rádio & 13 \\
\hline Conversas com amigos & 9 \\
\hline Outros meios. & 1 \\
\hline N & 1.550 \\
\hline
\end{tabular}

Fonte: Vox Populi, 1995.

Pergunta: "Nos últimos 3 meses, você tem lido, visto ou ouvido alguma notícia sobre a Assembleia Legislativa, seja na tv, rádio, em jornais ou qualquer outra forma?" (se sim, através de que meios de comunicação você tem recebido notícias sobre a Assembleia?) A questão possibilitava múltiplas respostas para aqueles que declaravam ter lido, visto ou ouvido alguma notícia sobre o trabalho da ALMG

Portanto, temos aqui algumas informações relevantes para os objetivos do presente artigo. Para a maioria dos mineiros, a ALMG se situa num espaço distante do seu mundo cotidiano, sem despertar interesse por informação. Se não se informa, é mais provável que a imagem que esse indivíduo tenha do legislativo estadual seja resultado de processos variados, passando pela recepção de informação "gratuita" e de maior destaque (ex: a primeira página dos jornais ou as chamadas do noticiário da noite) e por certos "atalhos", como, por exemplo, ao associar a imagem vaga que tem dos políticos e instituições políticas em geral à sua avaliação do legislativo estadual. Esse é, portanto, o segmento da sociedade mais suscetível ao efeito de contaminação apontado anteriormente ${ }^{23}$.

Por outro lado, uma minoria se informa não apenas através das mensagens produzidas pelos meios convencionais de comunicação, mas também por mensagens produzidas pela própria Assembleia. É esse público que está

\footnotetext{
23 Seguimos aqui o conflituoso legado de Converse (1964), nos estudos sobre atitudes e comportamento político, que confere valor explicativo ao grau de sofisticação política do cidadão. Para uma avaliação preliminar das apropriações, mais ou menos críticas, deste legado, ver Zaller (1992); Zaller \& Feldman (1992); Luskin (1987; 1990); Sears \& Valentino (1997); Althaus (2003); McGraw (2000).
} 
diretamente exposto às estratégias de comunicação da ALMG e à cobertura cotidiana dos meios de comunicação ${ }^{24}$.

A Tabela 6 apresenta a evolução temporal - entre 1995 e 2006 - do nível de informação do mineiro a respeito das atividades da ALMG. Esses resultados qualificam os apresentados na tabela anterior, indicando uma relativa estabilidade tanto daqueles que consideram ter muita informação como daqueles que declaram que não têm nenhuma informação sobre a ALMG.

No entanto, após 2001, há um ligeiro declínio no número de mineiros que se consideram, minimamente, informados. O público com "pouca informação" e "muita informação", que, em 1995, somava 38\%, cai para 30\%, em 2003, mantendo-se no mesmo patamar em 2006. É possível que esse declínio na autopercepção do nível de informação sobre a ALMG guarde alguma relação com o fato de que o principal esforço institucional de divulgação de informações sobre a Assembleia, o Assembleia Informa, deixou de ser veiculado em 2001.

\section{Tabela 6}

Percepção de informação sobre as atividades da ALMG (\%)

\begin{tabular}{|l|c|c|c|c|}
\cline { 2 - 5 } \multicolumn{1}{c|}{} & $\mathbf{1 9 9 5}$ & $\mathbf{2 0 0 1}$ & $\mathbf{2 0 0 3}$ & $\mathbf{2 0 0 6}$ \\
\hline Tem muita informação a respeito & 4 & 6 & 3 & 5 \\
\hline Tem pouca informação & 34 & 30 & 27 & 27 \\
\hline Não tem quase nenhuma informação a respeito & 22 & 19 & 26 & 23 \\
\hline Não tem nenhuma informação a respeito & 40 & 45 & 43 & 43 \\
\hline Não respondeu & 0 & 0 & 0 & 1 \\
\hline N & 1.550 & 1.500 & 5.000 & 6.300 \\
\hline
\end{tabular}

Fonte: Vox Populi, 1995, 2001, 2003, 2006.

Pergunta: "Em relação ao trabalho que a Assembleia Legislativa de Minas Gerais vem realizando atualmente, você diria que".

Esses números são bastante persuasivos: a ALMG é, praticamente, invisível para um expressivo segmento da sociedade mineira ${ }^{25}$. Assim como vimos em

\footnotetext{
24 Apesar de não termos meios de avaliar se são as mesmas pessoas que assistem o noticiário da televisão, o noticiário do rádio e o programa Assembleia Informa, supomos que há uma substantiva sobreposição entre essas audiências, constituindo o público atento às notícias políticas.

25 A distância entre a sociedade e o legislativo mineiro acentua-se quando passamos da esfera da informação para o campo do comportamento. O número reduzido dos entrevistado que declaram já terem ido à Assembleia (8\%) cai para $1 \%$ quando consideramos apenas aqueles que frequentaram a ALMG para participar de reuniões de plenário ou comissões.
} 
relação à confiança em instituições políticas, esse quadro de desinformação coincide com o que encontramos sobre política em geral no Brasil ${ }^{26}$.

Mas, quais seriam os segmentos socioeconômicos da sociedade mineira que constituem esses públicos? A resposta é simples e direta, pois a distribuição de informação a respeito da ALMG segue um padrão bem definido: o percentual de desinformados é inversamente proporcional à escolaridade (Tabela 7) e à renda (Tabela 8$)^{27}$. Ou seja, os indivíduos com maiores recursos cognitivos e materiais são os que mais declaram maior nível de informação sobre a Assembleia. No entanto, mesmo entre os grupos de escolaridade e renda mais altas, o percentual daqueles que julgam ter muita informação sobre a ALMG não chega a 10\% em 2006.

Tabela 7

Percepção de informação sobre as atividades da ALMG por nível de escolaridade (\%)

\begin{tabular}{|l|c|c|c|c|}
\cline { 2 - 5 } \multicolumn{1}{c|}{} & $\begin{array}{c}\text { Até } \mathbf{4}^{\mathrm{a}} \\
\text { série } \\
\text { do EF }\end{array}$ & $\begin{array}{c}\text { De } 5^{\text {a }} \text { a } \mathbf{8}^{\mathrm{a}} \\
\text { séries do EF }\end{array}$ & $\begin{array}{c}\text { Ensino } \\
\text { Médio }\end{array}$ & $\begin{array}{c}\text { Ensino } \\
\text { Superior }\end{array}$ \\
\hline Tem muita informação a respeito & 3 & 5 & 6 & 9 \\
\hline Tem pouca informação & 20 & 26 & 35 & 40 \\
\hline $\begin{array}{l}\text { Não tem quase nenhuma } \\
\text { informação a respeito }\end{array}$ & 20 & 23 & 26 & 28 \\
\hline $\begin{array}{l}\text { Não tem nenhuma informação a } \\
\text { respeito }\end{array}$ & 55 & 46 & 32 & 22 \\
\hline NR & 2 & 1 & 1 & 2 \\
\hline $\mathrm{N}$ & 2.370 & 1.565 & 1.811 & 553 \\
\hline
\end{tabular}

Fonte: Vox Populi, 2006.

\footnotetext{
26 De acordo com o levantamento do Latinobarômetro, em 1996, mais de 60\% dos brasileiros não tinham o hábito de se informar sobre política, sendo que três quartos da população declaravam ter pouco ou nenhum interesse por política (MOISÉS, 2006).

27 Tais resultados seguem o mesmo padrão geral de outros estudos realizados sobre informação política como, por exemplo, Delli Carpini \& Keeter (1996); Fuks, Reis \& Fialho (2007); Neuman (1986).
} 
Tabela 8

Percepção de informação sobre as atividades da ALMG por nível de renda (\%)

\begin{tabular}{|l|c|c|c|c|}
\cline { 2 - 5 } \multicolumn{1}{c|}{} & $\begin{array}{c}\text { Até } \mathbf{1} \\
\text { SM }\end{array}$ & $\begin{array}{c}\text { De } \mathbf{1} \text { a 5 } \\
\text { SM }\end{array}$ & $\begin{array}{c}\text { De 5 a 10 } \\
\text { SM }\end{array}$ & $\begin{array}{c}\text { Mais de 10 } \\
\text { SM }\end{array}$ \\
\hline $\begin{array}{l}\text { Tem muita informação a } \\
\text { respeito }\end{array}$ & 2 & 4 & 6 & 9 \\
\hline Tem pouca informação & 21 & 27 & 31 & 36 \\
\hline $\begin{array}{l}\text { Não tem quase nenhuma } \\
\text { informação a respeito }\end{array}$ & 19 & 23 & 26 & 24 \\
\hline $\begin{array}{l}\text { Não tem nenhuma } \\
\text { informação a respeito }\end{array}$ & 56 & 44 & 36 & 30 \\
\hline NR & 2 & 1 & 0 & 1 \\
\hline $\mathrm{N}$ & 1.053 & 3.813 & 913 & 521 \\
\hline
\end{tabular}

Fonte: Vox Populi, 2006.

Como recurso cognitivo, informação também está, ela mesma, relacionada com diferentes percepções sobre a ALMG. No que diz respeito à relação entre informação e avaliação do trabalho realizado pela instituição, nota-se que aqueles que consideram ter muita informação sobre a ALMG apresentam quase o dobro de chance de avaliarem positivamente a instituição quando comparados com aqueles que dizem não ter nenhuma informação $(80 \% \text { a } 47 \%)^{28}$ (Tabela 9).

28 Outra evidência que corrobora a relação entre ter mais informação sobre a ALMG e uma visão mais positiva a seu respeito é o fato de que uma parcela significativa da audiência do programa Assembleia Informa afirmou, em 1993, ter mudado, no sentido favorável, sua opinião a respeito da ALMG (27\%). 
Tabela 9

Avaliação do trabalho realizado pela ALMG por grau de informação sobre a instituição (\%)

\begin{tabular}{|l|c|c|c|}
\cline { 2 - 4 } \multicolumn{1}{c|}{} & $\begin{array}{c}\text { Avaliação } \\
\text { positiva }\end{array}$ & $\begin{array}{c}\text { Avaliação } \\
\text { negativa }\end{array}$ & NS/NR \\
\hline Tem muita informação a respeito & 80 & 17 & 3 \\
\hline $\begin{array}{l}\text { Tem pouca } \\
\text { Informação }\end{array}$ & 66 & 28 & 6 \\
\hline $\begin{array}{l}\text { Não tem quase nenhuma } \\
\text { informação a respeito }\end{array}$ & 60 & 28 & 11 \\
\hline $\begin{array}{l}\text { Não tem nenhuma informação a } \\
\text { respeito }\end{array}$ & 46 & 26 & 28 \\
\hline
\end{tabular}

Fonte: Vox Populi, 2003.

Essa parcela da população, que apresenta ou considera ter maior contato com informações sobre a instituição, é o universo social para o qual as inovações institucionais são mais perceptíveis, contribuindo para uma mudança da imagem pública da ALMG.

\section{Conclusão}

Os limites que os dados disponíveis impõem à nossa análise impedem que possamos responder de forma mais direta e satisfatória a questão que nos interessa: se e em que medida as inovações institucionais que ocorreram na ALMG a partir do início da década de 1990, associadas a um intenso esforço de comunicação política, foram acompanhadas por uma mudança na imagem pública da instituição. O que nos propusemos fazer aqui foi identificar indícios e sugerir algumas interpretações.

A análise comparativa no tempo e com outras instituições políticas não nos autoriza a falar sobre uma excepcionalidade do legislativo mineiro no que se refere à sua imagem pública. Em grande medida, essa imagem, em termos de confiança e avaliação, não foge do padrão brasileiro em relação às instituições políticas. Além disso, a evolução temporal dessa imagem não indica nenhuma alteração expressiva da opinião pública. A exceção fica por conta do ano de 2001, provavelmente em função das dimensões assumidas nos meios de comunicação pelo escândalo dos mega-salários.

Por outro lado, apesar de modestos, há certos indícios de que as mudanças que ocorreram na ALMG e as estratégias que a própria instituição usou para melhorar a sua imagem provocaram algum efeito sobre segmentos da opinião 
pública mineira. Exemplo disso é a disseminação da percepção, com destaque para as pesquisas de 1995 e 2003, de que, comparada com "dez anos atrás", a ALMG melhorou. Mas os dados também mostram a fragilidade desse processo de mudança de imagem. Em parte porque, quando o indivíduo é convidado a pensar sobre a ALMG, ficam mais salientes em a sua mente os esquemas mentais a partir dos quais ele percebe o mundo da política e das instituições políticas brasileira (MCGRAW, 2000).

Além disso, como fica claro pelos retrocessos de 2006, e sobretudo, 2001, os episódios dramáticos e negativos, além de terem adquirido maior saliência pública do que as "boas notícias", tiveram um efeito devastador sobre a imagem pública da ALMG. As circunstâncias políticas parecem explicar melhor as atitudes políticas dos mineiros do que qualquer outra variável.

O que ficou mais evidente em nossa análise é que o estudo de efeitos de mudanças institucionais ou de estratégias persuasivas sobre a opinião pública deve levar em consideração a existência de diversos públicos, a começar pelos diferentes graus de interesse e atenção em relação ao assunto em questão.

O público constituído por indivíduos de alta escolaridade e renda mostrou-se mais atento e mais bem informado a respeito do que acontece na ALMG. Consideramos também o impacto diferenciado do processo de inovação institucional sobre um público muito específico: aqueles que consumiram as mensagens produzidas pela ALMG e veiculadas no rádio e na televisão. Esse público foi submetido às estratégias persuasivas da ALMG, com o objetivo de conferir maior visibilidade à instituição e promover uma imagem favorável da mesma. De fato, a audiência do programa Assembleia Informa mostrou-se, relativamente, mais bem informada e receptiva a uma imagem mais favorável da ALMG.

Não foi a intenção desse trabalho analisar, de forma sistemática, as causas da não-correspondência entre a excepcionalidade da ALMG no quadro dos legislativos subnacionais e sua imagem pública. No entanto, algumas linhas explicativas contribuíram para a análise dos dados. Uma delas foi a perspectiva da teoria da cultura política, apontando a inércia de uma visão tradicional e negativa que os brasileiros têm do mundo da política, tal como indicada pela ideia da "contaminação".

Também fizemos referência ao desinteresse pela política, expresso pelo baixo consumo de informação, o que impossibilita o reconhecimento público de qualquer esforço de mudança institucional. Há, na verdade, um duplo obstáculo à visibilidade pública da ALMG, formando um ciclo vicioso. O baixo interesse midiático em veicular informações a respeito da ALMG e o baixo interesse do cidadão em acompanhar o que acontece na instituição se reforçam reciprocamente.

Obviamente, nenhuma análise a respeito dos obstáculos na mudança da imagem de uma instituição política pode deixar de considerar a tese de que, apesar 
de todo o esforço de mudança institucional, a ação negativa dos políticos é responsável por uma imagem menos favorável do que se esperaria da ALMG.

Mas devemos também levar em consideração a perspectiva que atribui à mídia a responsabilidade pela ênfase na cobertura negativa. Em relação a esse aspecto, a "má notícia", de acordo com a nossa análise, é que a veiculação de eventos negativos tem efeitos devastadores sobre a imagem pública das instituições, enquanto eventos positivos, quando tornados públicos, apresentam efeitos bem limitados.

A boa notícia é que o impacto negativo não se propaga no tempo. Alterações mais profundas - positivas ou negativas - dependem de processos sociais mais complexos e duradouros, expressos em experiências reiteradas. Nesse sentido, podemos apostar que - apesar de já ter passado mais de uma década e meia - os frutos das inovações institucionais da ALMG ainda estão por vir, dependendo do longo tempo que envolve a transmissão de atitudes políticas mais consistentes e a ampliação dos segmentos que estabelecem contato direto com a instituição.

A complexidade da relação entre mudança institucional e imagem pública exige uma explicação que leve em consideração o conjunto desses fatores. Mas deixaremos para o próximo trabalho a tarefa de explorar melhor tal questão.

\section{Referências Bibliográficas}

ALTHAUS, S. Collective Preferences in Democratic Politics: Opinion Surveys and the Will of the People. New York: Cambridge University Press, 2003.

ALMOND, G. e VERBA, S. The Civic Culture: Political Attitudes and Democracy in Five Nations. Princeton: Princeton University Press, 1963.

ASSEMBLEIA LEGISLATIVA DE MINAS GERAIS. Desenvolvimento Institucional da Assembleia Legislativa do Estado de Minas Gerais. Relatório Institucional, 1994. 
. Desenvolvimento Institucional da Assembleia Legislativa do Estado de Minas Gerais 1988 a 1998. Relatório Institucional, 1999.

. Estrutura Organizacional e Visão Institucional da ALEMG. Relatório Institucional, 2002. Processo Licitatório n 72/2001. Edital de Concorrência n 003/2001, 2001. Processo Licitatório nº 56/2006. Edital de Concorrência nº 004/2006, 2006.

ASSIS, L. F. "Educando para a Cidadania: A Experiência da Escola do Legislativo". Educação \& Sociedade. n59, p.367-385, 1997.

BRAGA, S. S. O Impacto da Internet no Funcionamento das Instituições Democráticas Brasileiras: Um Estudo sobre a Informatização dos Legislativos Estaduais no Brasil. II Congresso da Associação Latinoamericana de Ciência Política. Cidade do México, 29 set. - 1 out. 2004.

BRASIL. Lei n 8.977, de 6 de Janeiro de 1995. Diário Oficial da União, Brasília, 9 de Janeiro de 1995.

CONVERSE, P. The Nature of Belief Systems in Mass Publics. In: APTER, D. (org.) Ideology and Discontent. New York: The Free Press, 1964.

DELLI CARPINI M. X., \& KEETER, S. What Americans Know about Politics and Why It Matters. London: Yale University Press, 1996.

DULCI, O. e FARIA, M. A. Diálogo com o Tempo - 170 anos do Legislativo Mineiro. Belo Horizonte: Assembleia Legislativa do Estado de Minas Gerais, 2005. 
FUKS, M.; REIS, B. e FIALHO, F. M. Desigualdades sociais e cultura política em Belo Horizonte. XIII Congresso Brasileiro de Sociologia. Recife, 29 maio - 1 jun. 2007.

JARDIM, M. A. "O mapa da mídia eletrônica legislativa na América Latina". $3^{\circ}$ Congresso Latino-Americano de Ciência Política, Unicamp, Campinas.

KLINGEMANN, H.D. Mapping Political Support in the 1990s: A Global Analysis. In: NORRIS, P. (ed.). Critical Citizens: Global Support for Democratic Government. Oxford: Oxford University Press, 1999.

LAGOS, M. "A Máscara Sorridente da América Latina". Opinião Pública, vol. 6, nº1, p.1-16, 1987.

LÉLIO FABIANO e ASSOCIADOS COMUNICAÇÃO EMPRESARIAL. Planejamento Estratégico de Comunicação Social para a Assembleia Legislativa de Minas Gerais. Relatório, 1990.

LUSKIN, R. C. "Measuring political sophistication". American Journal of Political Science, vol.31, n4, p.856.899, 1987.

“Explaining Political Sophistication". Political Behavior, vol.12, n4, p.331-361,

1990.

MCGRAW, K. M. "Contributions of the Cognitive Approach to Political Psychology". Political Psychology, vol.21, nº, p.805-832, 2000.

MOISÉS, J. A. A avaliação das Instituições Democráticas e a Qualidade da Democracia no Brasil. XX Congresso Mundial da IPSA. Fukuoka, 8 - 13 de jul. 2006.

NEUMAN, W. R. The Paradox of Mass Politics: Knowledge and Opinion in the American Electorate. Cambridge: Harvard University Press, 1986. 
NORRIS, P. A Virtuous Circle: Political Communications in Postindustrial Societies.

Cambridge: University Press, 2000.

PATEMAN, C. Participação e Teoria Democrática. Rio de Janeiro: Paz e Terra, 1992.

POWER, T. e JAMISON, G. "Desconfiança Política na América Latina". Opinião Pública. vol.11, $n^{\circ} 1$, p.64-93, 2005.

PUTNAM, R. D. Comunidade e Democracia: A Experiência da Itália Moderna. Rio de Janeiro: Fundação Getúlio Vargas, 1996.

RENAULT, L. Comunicação e Política nos Canais de Televisão do Poder Legislativo. Belo Horizonte: Assembleia Legislativa do Estado de Minas Gerais, 2004.

SEARS, D. O. VALENTINO, N. A. "Politics Matters: Political Events as Catalysts for Preadult Socialization". American Political Science Review, vol.91, nº 1, p.45-65, 1997.

SOUSA, D. B. Mega-Salários: O Escândalo Midiático em um Contexto de Mudança Institucional na Assembleia Legislativa de Minas Gerais. I/ Congresso da Associação Brasileira de Pesquisadores em Comunicação e Política. Belo Horizonte, 5 - 7 dez. 2007.

VOX POPULI. "Desinformação Alimenta Descrença”. Revista do Legislativo, n5 p.10-13, 1993.

ZALLER, J. The Nature and Origins of Mass Opinion. Cambrige: Cambrige University Press, 1992.

The Myth of Massive Media Impact Revived: New Support for a Discredited Idea. In: MUTZ, D.; SNIDERMAN, P. e BRODY, R. (eds.). Political Persuasion and Attitude Change. Ann Arbor: University of Michigan Press, 1996. 
ZALLER, J. e FELDMAN, S. "A Simple Theory of the Survey Response: Answering Questions versus Revealing Preferences". American Journal of Political Science, vol.36, n.2, p.579-616, 1992.

\section{Anexo}

A Tabela A1 traz informações sobre margem de erro, tamanho da amostra e ponderações, e datas de realização das pesquisas realizadas pela Vox Populi e utilizadas neste artigo. Para as cinco pesquisas realizadas, o intervalo de confiança é de $95 \%$.

\begin{tabular}{|l|l|l|l|l|l|}
\hline \multicolumn{7}{|c|}{ Tabela A1 } \\
\hline & 1993 & 1995 & 2001 & 2003 & 2006 \\
\hline $\begin{array}{l}\text { Datas de realização do } \\
\text { campo }\end{array}$ & $\begin{array}{l}23 / 10 \\
26 / 10\end{array}$ & $\begin{array}{l}16 / 10 \text { a } \\
19 / 12\end{array}$ & $\begin{array}{l}9 / 10 \text { a } \\
11 / 10\end{array}$ & $\begin{array}{l}23 / 07 \text { a } \\
25 / 07\end{array}$ & $\begin{array}{l}23 / 08 \text { a } \\
31 / 08\end{array}$ \\
\hline Dimensão da amostra & 1.503 & 2.679 & 2.494 & 5.000 & 6.300 \\
\hline $\begin{array}{l}\text { Amostra ponderada para } \\
\text { o total do estado }\end{array}$ & 1.153 & 1.550 & 1.500 & 5.000 & 6.300 \\
\hline Margem de erro & $2,5 \%$ & $2,5 \%$ & $2,5 \%$ & $1,4 \%$ & $1,2 \%$ \\
\hline
\end{tabular}

Fonte: Vox Populi, 1993, 1995, 2001, 2003, 2006.

Mario Fuks.mariofuks@uol.com.br

Fabricio Mendes Fialho Fialho - fabriciofialho@gmail.com

Recebido para publicação em julho de 2008.

Aprovado para publicação em março de 2009. 